\title{
ALMEIDA JUNIOR E A FOTOGRAFIA: UMA NOVA DIMENSÃO DA OBRA DO ARTISTA
}

Suzana Barretto Ribeiro ${ }^{1}$

\section{Resumo:}

Durante a fase regionalista da pintura de Almeida Junior, é nítida a influência e as mudanças proporcionadas pelo uso da fotografia. O crítico Ernesto de Sousa Campos, já na década de 50, analisa a obra Apertando o Lombilho (1895) e a caracteriza como "um exato instantâneo do que estamos habituados a ver ao longo das estradas". Entre os pesquisadores da obra do artista, este é o primeiro a fazer referência à presença da característica do instantâneo. No entanto, apesar de reconhecer a peculiaridade da experiência formal, o autor não chega a estabelecer uma possível relação do uso da fotografia como modelo pictórico. $\mathrm{Na}$ análise das obras Amolação Interrompida (1888), Caipira picando fumo (1892) e Caipiras negaceando (1888), a incorporação do instantâneo pode ser ainda melhor observada. Nestas telas, a gestualidade do protagonista está centrada na nitidez do registro, no potencial significante do enquadramento e na exploração dos efeitos de luz. Essa nova atitude formal proporciona algumas hipóteses; a primeira é a de que o artista ao estabelecer diálogo com fotógrafos e literatos interessados em aspectos singulares da cultura do interior paulista estabelece trocas que irão interferir na representação pictórica. A outra, é a de que a obra do artista incorpora o uso e a exploração de características específicas da técnica fotográfica. Rever o processo de instauração das transformações pictóricas pelo viés da fotografia é o desafio que perpassa a comunicação.

Palavras-chave: Fotografia; Pintura; Regionalismo

O pintor Almeida Junior, após conquistar carreira de prestígio internacional, se recusa às regalias garantidas pela permanência na corte $\mathrm{e}$, neste momento volta às origens. Abandona o realismo burguês e parte em busca de um realismo de orientação regionalista, mais comprometido com os hábitos do caipira e com a luz do interior paulista.

Neste período que vai de 1888 a 1898 vão surgir as grandes composições de caráter regionalista, que hoje lhe garantem prestígio talvez superior às pinturas realizadas na França: Caipiras Negaceando, Cozinha Caipira, Amolação Interrompida, Caipira picando Fumo, O Violeiro. No mesmo período, registra também paisagens de Itu e imediações, e ainda, retratos de conhecidos.

Durante essa fase, é nítida a influência e as mudanças proporcionadas pelo uso da fotografia. Já na década de 50, o crítico Ernesto de Sousa Campos, em artigo dedicado a Almeida Junior, analisa a obra Apertando o Lombilho (1895) e a caracteriza como "um exato instantâneo do que estamos habituados a ver ao longo das estradas". 2

Entre os pesquisadores da obra do artista, Sousa Campos será o primeiro a fazer referência à presença de uma característica peculiar ao ato fotográfico: o registro do instante, do fragmento e do gesto fugidio. Infelizmente, para os historiadores da arte, apesar de

\footnotetext{
${ }^{1}$ Departamento de Design - Faculdade de Administração e Artes de Limeira, suzanabarretto@terra.com.br

${ }^{2}$ Ernesto de Sousa Campos. José Ferraz de Almeida Junior. Revista do Instituto Histórico e Geográfico do Estado de São Paulo. São Paulo, v. L, p. 94-7. 1953.
} 
reconhecer a peculiaridade da experiência formal, o autor não chega a estabelecer uma possível relação entre a fotografia e a obra pictórica do artista.

Ao apontar para esta característica intrínseca à fotografia, Sousa Campos muito provavelmente não se deu conta dos desdobramentos possíveis, caso viesse aprofundar a questão. Quase sessenta anos após a publicação do artigo, o tema permanece inédito e ainda mais atual, em função da intensa apropriação da fotografia pela arte visual contemporânea.

Diante de tais considerações, o foco desta comunicação incidirá inicialmente sobre hipóteses e possibilidades relacionadas ao uso da fotografia em algumas das obras produzidas por Almeida Junior. Tais exemplares, no entanto, serão considerados no circuito social em que foram produzidos; daí a necessidade de revisitar, mesmo que rapidamente as relações estabelecidas entre o artista, fotógrafos e literatos, que, antes mesmo dos modernistas, estavam preocupados com a construção de uma arte genuinamente brasileira.

Noutros termos, essa produção elaborada por pré-modernistas articulava técnicas e formas de expressão ainda pouco exploradas por artistas daquele período. Para demonstrá-las, é preciso antes de tudo examinar as obras e as técnicas que envolvem o processo produtivo desta fase de Almeida Junior. Começo pela incorporação de uma nova forma de gestualidade caracterizada pela seleção e apropriação do instante.
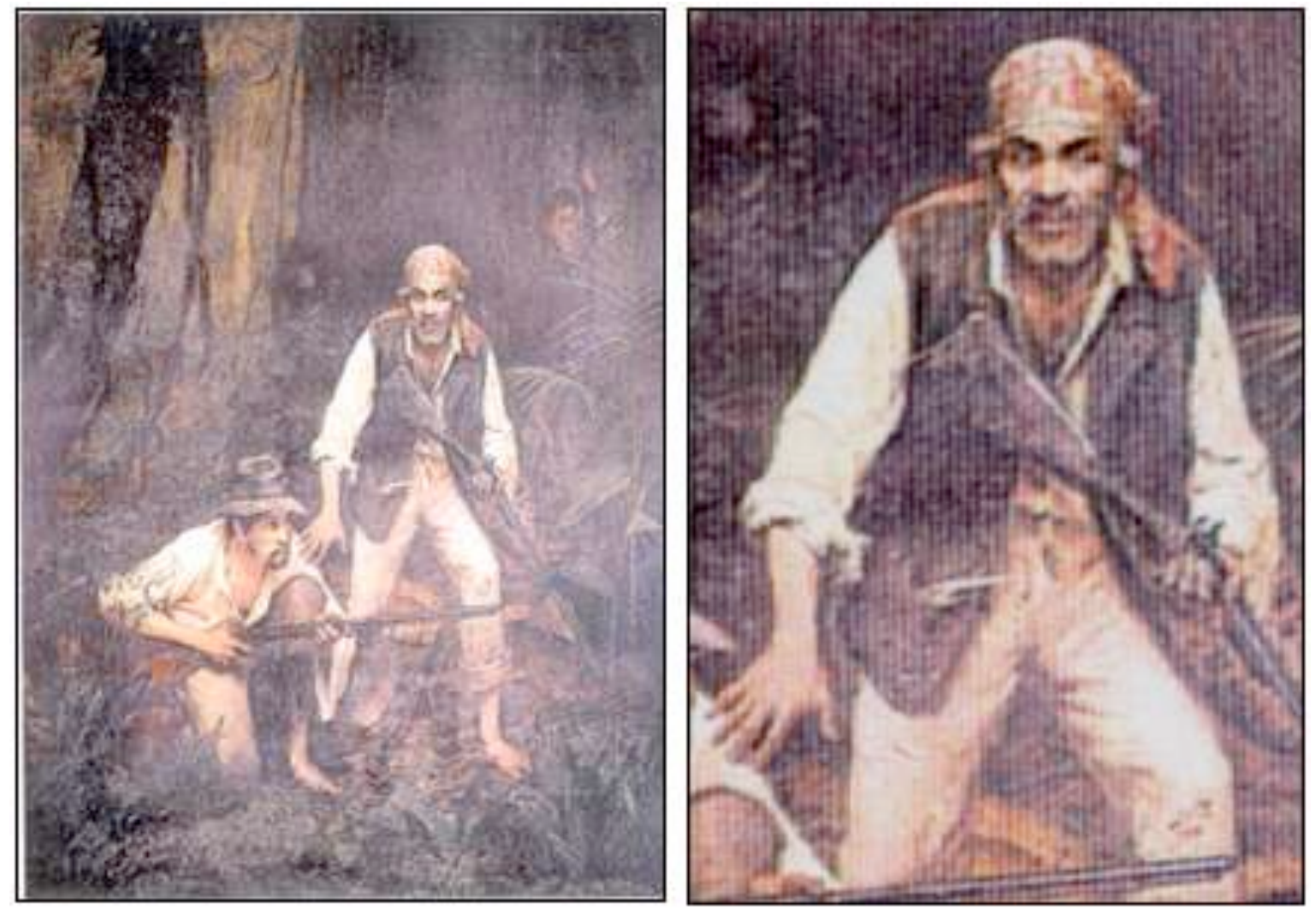

Em Amolação Interrompida (1888) e Caipiras negaceando (1888), essa característica pode ser mais notadamente observada. Nas obras em questão, as características do homem do campo 
ganham concretude e, simultaneamente, tornam-se mais próxima do imaginário popular; a gestualidade dos protagonistas é registrada com a preocupação em apreender o instante, mesmo que posado, numa atitude explicitamente fotográfica, merecendo consideração não só a repetição do tema, mas também a situação de cumplicidade representada na relação entre caçadores.

Nestas obras, a composição pictórica já aponta para aquilo que a linguagem fotográfica tem de específico e de precursor nas mudanças dos padrões de visualidade: o instantâneo, fortes contrastes, traços sintéticos e ênfase sobre o primeiro plano.

De acordo com a tendência apontada nestas obras, já está presente uma estética regionalista, baseada não só na valorização daquilo que a natureza e a cultura local poderiam oferecer, mas também na espontaneidade dos registros e na escolha de temas da vida cotidiana, tomados de forma simples.

A postura adotada na representação de mundo reflete também o grau de necessidade interior que rege a escolha do tema, do momento selecionado e da concepção que o artista ainda mantém da vida do homem do interior de São Paulo. Chama a atenção, o fato de que neste momento, a opção é dada pela inserção de uma paisagem quase intacta, sem as modificações advindas da produção cafeeira. Esse recorte, entretanto, é bastante distinto daquele que prevalece na região retratada, onde a vegetação local foi transfigurada em infinitos cafezais e nas quais são encontrados os maiores índices de produção de café daquele período.

A despeito de tais alterações sobre a paisagem e os costumes, olhar do artista irá se caracterizar por um processo seletivo que pinça situações as quais intenciona preservar.

Além do conteúdo narrativo, os autores têm em comum a aproximação com o personagem retratado: a inserção do homem em seu espaço cotidiano, a identificação dos costumes, bem como uma forte cultura gestual. Tal peculiaridade destes autores se caracteriza como elemento revelador, de um lado, da intimidade e do conhecimento partilhado desse universo e, de outro, prevalece como forte característica, a resistência em incorporar aspectos e costumes mais pertinentes ao modo de vida urbano, que naquele momento passa por transformações radicais advindas de influências das capitais européias e que repudiavam qualquer tipo de herança colonial e interiorana.

Um outro exemplo importante é o Caipira Picando fumo - o ícone do caipira que, não fosse a semelhança com outras obras, não levantaria suspeita no que diz respeito a sua relação com a fotografia.

No entanto, ao se realizar uma análise comparativa da tela Caipira picando fumo (1892) e da fotografia que tem como legenda: Um caçador de porcos com mais de oitenta anos. Agora só pitando. (primeira década do século XX), merece atenção o fato de que na pintura, o autor opta por colocar seu personagem em situação introspectiva, envolvido com a tarefa de picar o fumo. Já na fotografia, a presença da câmera é denunciada pelo olhar do personagem retratado em direção à objetiva do fotógrafo. 


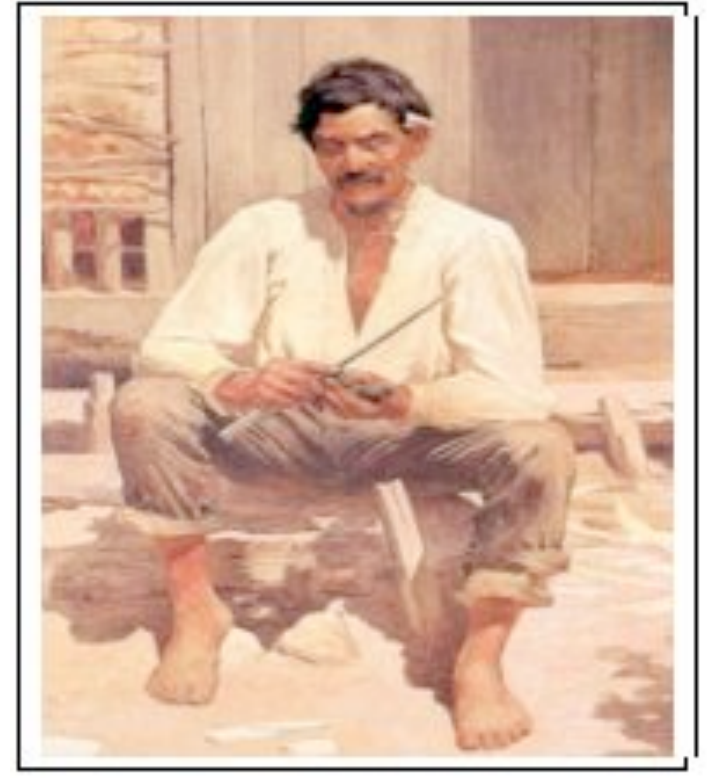

Caipira picando fumo (1892) Almeida Junior

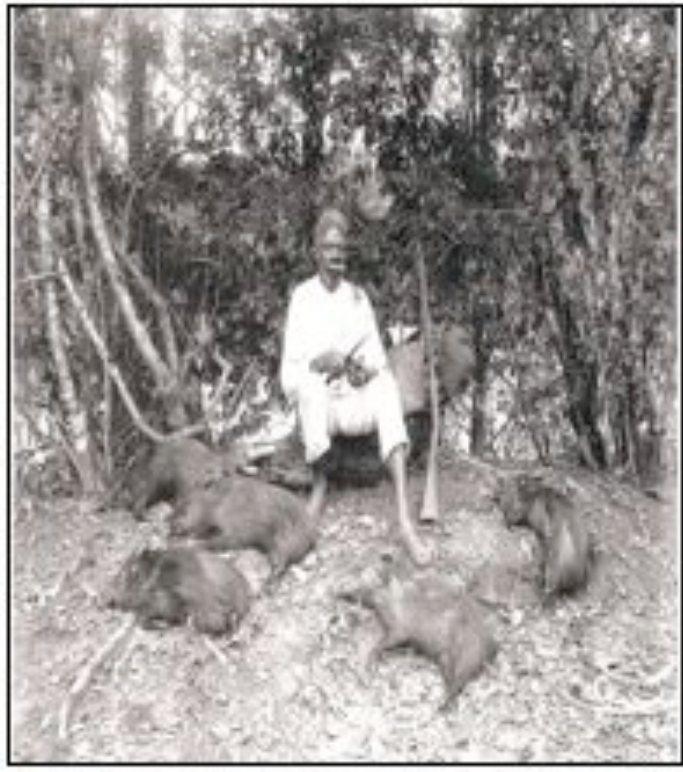

Um cafador de porcos com mais de oitenta anos. Agora só pitando. (Primeira década do século $X X$ )

A intensa divulgação da imagem do Caipira picando fumo confirma uma preocupação que traz inúmeras contribuições para o pré-modernismo brasileiro. Não é por acaso que Monteiro Lobato se refere a tal imagem da seguinte maneira:

Des'que Almeida Junior, o artista educado lá que melhor reagiu contra a corrente, rasgou picadas novas com o seu picador de fumo, não houve espreme-bisnagas que se não julgasse obrigado a pagar esse tributo de capitação ao caipira. A modos que, lá pelo ano 3.000, a arqueologia restauradora da nossa época por meio das telas coevas chegará a uma única conclusão: naquela metade de século, no Brasil, o caipira picava fumo. Só, mais nada.

No campo da literatura, o mesmo interesse é demonstrado pelos temas vinculados a elementos próprios de uma cultura regional e reveladores de situações cotidianas e paisagens. Valdomiro Silveira e Euclides da Cunha referem-se ao caipira em situações díspares, densas de dramaticidade, com total familiaridade e domínio do vocabulário, tal como se pode observar no conto "Tocaia", de Silveira, datado de 1904.

Espreitou o mato, em roda de uma urtiga de machado, agachou-se para mais observar o escuro de entre as raízes das árvores e o mistério das baixadas cobertas de folhagem velha, pôs ainda a cabeça no caminho, olhando para cima e para baixo, sentou-se. E o coração, como se andasse cansado de uma carreira longa e dificultosa, pegou a roncarlhe o peito, com batidos rápidos, ao mesmo tempo que a vista se lhe baralhava e um grande fogo lhe subia ao rosto seco. Sentou-se, deitou a espingarda a um lado, raspou o tira-cisma numa palha de milho, cortou-a, aparou-a, picou fumo, fez um cigarro. Depois, encostado a um tronco de almécega, entrou a pensar na vida, iroso e aterrorizado, como aquele que já não tem nada que perder, afora o medo... ${ }^{3}$.

\footnotetext{
3 Valdomiro Silveira. Nas serras e nas furnas: contos. Rio de Janeiro: Civilização Brasileira, 1975.
} 
Com a apresentação desse conto, podemos estabelecer uma relação entre a pintura, a literatura e a fotografia, traduzindo, nesse caso, a busca da expressão de uma realidade próxima e em processo de intensa transformação. A semelhança entre formas de representação se sobrepõe e, nos dá a impressão de que se fala sempre de um único caipira, numa situação também única.

$\mathrm{Na}$ análise da obra do fotógrafo Austero Penteado, em função da utilização dos mesmos recursos de composição e dos mesmos elementos temáticos, interessava investigar a relação do fotógrafo com a pintura e, no decorrer do processo acreditava-se na referência da pintura para a fotografia.

$\mathrm{Na}$ obra de Almeida Junior, esse anseio pelo conhecimento/reconhecimento daquilo que seria valorizado anos mais tarde como manifestação de uma cultura nacional é enfatizado por Aracy Amaral, que, ao analisar a obra do artista, detecta "uma luz regionalista, de mau gosto, uma preocupação com o espírito local". 4

Historiadores da arte, de modo geral, ocuparam-se com a luz, com a temática adotada, de forma que a preocupação em registrar situações voltadas para a valorização das raízes e do modo de vida interiorano parecia ter um sentido bem mais preciso.

No entanto, o exame das relações e intenções que determinam, não só o fazer pictórico, literário e fotográfico, mas também a própria trajetória do pintor, do escritor e do fotógrafo, pode revelar concepções e formas de olhar comprometidas com princípios instituintes da arte moderna no Brasil.

A obra fotográfica de Austero Penteado instiga-nos a refletir sobre os laços que a atam à pintura e à literatura. O fotógrafo parece render tributos a situações cotidianas que excluem elementos indicadores de mudanças.

Ao mesmo tempo, essa simetria entre os interesses representados nas obras fotográfica, pictórica e literária possibilita reconhecer os símbolos arquetípicos da vida no interior, os quais povoam o inconsciente, num momento de transição das artes no Brasil caracterizado pela busca de uma nova orientação que valorize a cultura local.

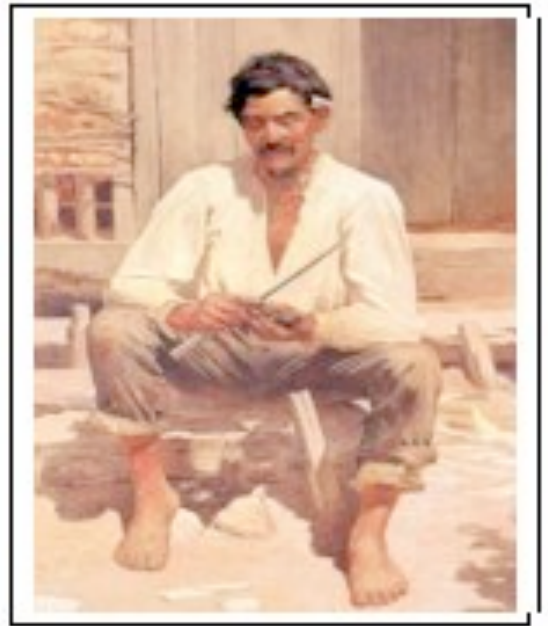

Caipira picando fumo (1892) Almeida Jr.

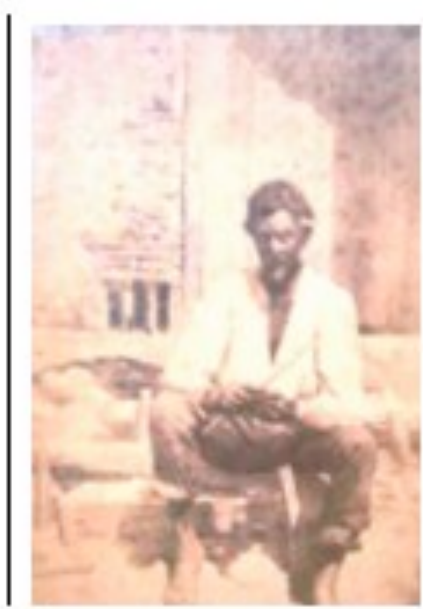

Luiz \& Steidel

${ }^{4}$ Luís Martins. 1952. Op. cit. 
Apenas recentemente, a descoberta da fotografia produzida pelo estúdio Luiz \& Steidel a qual foi utilizada pelo pré-modernista como modelo para seu caipira, ao mesmo tempo em encerra um ciclo de referências, abre para novas discussões à respeito do universo da representação do artista.

Com isso, a pintura de Almeida Junior nos instiga ainda mais, uma vez que à sua maneira, pode ser considerado duplamente precursor, seja pela busca de uma temática nacional, seja pela inserção da fotografia em seu processo criativo.

Em paralelo, as obras despertam um sentido crítico capaz de provocar reflexões que dizem respeito às possibilidades de troca entre a pintura, a literatura e a fotografia. Assim, não se trata aqui de uma contraposição entre essas formas de representação, mas de verificar possibilidades de diálogo entre elas.

\section{Bibliografia}

CAMPOS, Ernesto de Sousa. José Ferraz de Almeida Junior. Revista do Instituto Histórico e Geográfico do Estado de São Paulo. São Paulo, v. L, p. 94-7. 1953.

FABRIS, Annateresa (Org.). Modernidade e Modernismo no Brasil. Campinas, SP. Mercado de Letras, 1994.

SILVEIRA, Valdomiro. Nas serras e nas furnas: contos. Rio de Janeiro: Civilização Brasileira, 1975. 